\title{
Increased prevalence of hyperthyroidism as an early and transient side-effect of implementing iodine prophylaxis
}

\author{
Filip Gołkowski*, Monika Buziak-Bereza, Małgorzata Trofimiuk, Agata Bałdys- \\ Waligórska, Zbigniew Szybiński and Bohdan Huszno \\ Department of Endocrinology, Jagiellonian University Faculty of Medicine, Kopernika 17, $31-501$ Krakow, Poland
}

Submitted 21 February 2006: Accepted 26 September 2006: First published online 27 February 2007

\begin{abstract}
Objective: To assess the prevalence of hyperthyroidism just after implementation of iodine prophylaxis among adults from an area with iodine deficiency.

Study design and subjects: A total of 1648 adults (age 16 years and older) were sampled from an area of southern Poland during two nationwide epidemiological surveys. Of these, 1424 adults with negative medical history for thyroid disorders qualified for final analysis. The authors compared thyroid dysfunction in participants prior to (1989-1990) and after implementation of iodine prophylaxis (1997-1999). Setting: The southern part of Poland.

Results: We found an increase in the serum concentration of anti-thyroid microsomal antibodies from $4.9 \%$ in the years 1989-1990 to $12.1 \%$ after introduction of iodised household salt $(P<0.0001)$. The prevalence of hyperthyroidism (defined as thyroidstimulating hormone $<0.4 \mu \mathrm{U} \mathrm{ml}^{-1}$ ) significantly increased in the equivalent period from 4.8 to $6.5 \%(P=0.009)$.

Conclusions: We concluded that a sudden rise in iodine intake after implementation of iodine prophylaxis among adults from the area with iodine deficiency may lead to an increase in thyroid autoimmunity and prevalence of hyperthyroidism. Those possible early side-effects appear to be only temporary and are acceptable when compared with the evident benefits of adequate iodine intake.
\end{abstract}

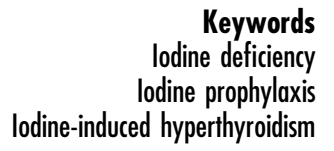

The southern part of Poland at the end of the 20th century was a region of moderate iodine deficiency.

The Polish Council for Control of Iodine Deficiency Disorders (PCCIDD), a member of the International Council for Control of Iodine Deficiency Disorders (ICCIDD), was established in 1991. In 1992-1995, three scientific programmes on iodine deficiency were carried out. The results of those investigations led to the conclusion that, according to ICCIDD criteria, the area of southern Poland is a region of moderate iodine deficiency ${ }^{1}$. Based on these results, the Ministry of Health and Social Welfare introduced, in January 1997, a mandatory model of household salt iodisation $(30 \pm 10 \mathrm{mg} \mathrm{KI}$ perkg of household salt). After that, further studies aimed at monitoring the benefits and possible side-effects were performed. The possibility of increased prevalence of hyperthyroidism and thyroid autoimmunity, in addition to changes in the thyroid cancer histotype, are the main areas of interest in that aspect of monitoring. Hyperthyroidism, particularly in at-risk groups with thyroid autonomy or subclinical hyperthyroidism, was shown to occur ${ }^{2}$.

Two other nationwide epidemiological surveys on thyroid morbidity were performed in the years 1989-1990 and 1997-1999 in Poland. The first study (1989-1990) was aimed at evaluating thyroidal consequences of the Chernobyl nuclear power station accident ${ }^{3}$. The second phase of this study was carried out in the years 1997-1999 to evaluate the same population after implementation of the mandatory model of iodine prophylaxis. The aim of this study was to assess the possible early side-effects of iodine prophylaxis implementation in adults from an area of moderate iodine deficiency.

\section{Materials and methods}

In the first phase of the survey (1989-1990), a random sample of 4176 adults (aged 16 years and older, mean age $37.5 \pm 13.3$ years) living in the geographical region of southern Poland (voivoidship Krakow, voivoidship Nowy Sacz and the area of the Kielce and Swietokrzyskie Mountains) was selected. The analysed group consisted of 1648 participants who, having been examined during the first phase, answered the invitation and took part in the second phase of the study in the years 1997-1999. A total of 1424 adults with no thyroidal therapy in their past medical history qualified for the final evaluation. Each of 
these subjects was examined twice - prior to and after implementation of iodine prophylaxis (the first and second phase of the survey).

In both phases of the survey, detailed assessment of the investigated subjects was achieved by means of a unified questionnaire (profiled towards thyroid disorders) and a series of medical and laboratory examinations ${ }^{4}$. In the first phase, plasma level of thyroid-stimulating hormone (TSH) was determined using an immunoenzymatic assay (Abott, Germany; functional sensitivity $=0.01 \mu \mathrm{U} \mathrm{ml}^{-1}$ ), and the total thyroxine $\left(\mathrm{T}_{4}\right)$ level using a radioimmunological assay (OPIDI Swierk, Poland). The serum concentration of anti-thyroid microsomal antibodies (ATMAs) was measured using an immunoenzymatic assay (HTL Plastomed, Poland). In the second phase, plasma TSH level was determined using a immunoradiometric assay (Byk Gulden, Germany), and plasma level of free thyroxine $\left(\mathrm{FT}_{4}\right)$ using an electrochemiluminescence assay (Roche, Switzerland). The serum concentration of ATMAs was measured using an immunoenzymatic assay (Diamed Lab., Poland). The urine iodine concentration was determined by the modified Sandell-Kolthoff catalytic method ${ }^{5}$. An ultrasound examination of the thyroid gland was performed by means of a Kontron Sigma 1L device with a $7.5 \mathrm{MHz}$ linear transducer. TSH determinations in both phases of the study were performed using third-generation TSH assays with functional sensitivity equal to $0.01 \mu \mathrm{Uml}^{-1}$.

In our study, subjects with a plasma TSH level $<0.4 \mu \mathrm{U} \mathrm{ml}^{-1}$ were qualified as having hyperthyroidism, and those with a plama TSH level $>4.5 \mu \mathrm{U} \mathrm{ml}^{-1}$ as having hypothyroisdism. This is in accordance with the reference range for the TSH level for the investigated population and with values accepted in other studies. The diagnosis of overt hyperthyroidism or hypothyroidism was made if values of $\mathrm{T}_{4}$ (first phase) or $\mathrm{FT}_{4}$ (second phase) were outside the normal range. The normal range for $\mathrm{T}_{4}$ was $4.4-12.5 \mu \mathrm{g} \mathrm{dl}^{-1}$ and for $\mathrm{FT}_{4} 7.7-23.2 \mathrm{pmoll}^{-1}$. The fact that in the first phase of the survey total thyroid hormone levels were determined, and in the second phase only $\mathrm{FT}_{4}$ (without free tri iodothyronine) was measured, makes it difficult to distinguish unambiguously between overt and subclinical hyperthyroidism in every case. That is why we use only the general term hyperthyroidism.

Statistical analysis was carried out using the package SAS version 9.1. The distributions of variables were different from normal (confirmed by Shapiro-Wilk test). Thus, nonparametric methods were used in a statistical analysis. The differences between independent samples were assessed by means of the Mann-Whitney test. The Wilcoxon signed rank and the McNemara tests were used to evaluate paired differences of variables before and after the implementation of the iodine prophylaxis. The Spearman's rank correlation and the contingency analysis were also used. A $P$-value $<0.05$ was considered as significant.

\section{Results}

The group consisting of 1648 adults (aged 16 years and older) was studied first in the years 1989-1990 and then again in the years 1997-1999.

For further analysis concerning possible changes in terms of frequency of hyperthyroidism after implementation of the iodine prophylaxis, all those undergoing therapy for thyroid disorder were excluded.

Finally, 1424 subjects were assessed. The characteristics of the investigated group are presented in Table 1.

The plasma TSH level was significantly higher in the whole group after implementation of the iodine prophylaxis. The prevalence of positive titres of ATMA increased significantly from 4.9 to $12.1 \%$ after iodine prophylaxis started $(P<0.0001)$. The prevalence of hyperthyroidism (defined as TSH $<0.4 \mu \mathrm{U} \mathrm{ml}^{-1}$ ) increased significantly in the equivalent period of time from 4.8 to $6.5 \%(P=0.009)$ (Fig. 1). The prevalence of hypothyroidism (defined as $\mathrm{TSH}>4.5 \mu \mathrm{Uml}^{-1}$ ) increased from 1.3 to $3.1 \%$ in that period $(P<0.05)$.

In the years 1989-1990 in 15\% of these cases, a low plasma TSH level was accompanied by an increased serum $\mathrm{T}_{4}$ concentration. In the years $1997-1999$ in $12 \%$ of these cases, a low plasma TSH was accompanied by an increased serum $\mathrm{FT}_{4}$ concentration. The median value of total $\mathrm{T}_{4}$ in 1989-1990 was $8.4 \mu \mathrm{g} \mathrm{dl}^{-1}$ (interquartile range $(\mathrm{IQR})=3.0 ;$ normal range $=4.4-12.5 \mu \mathrm{g} \mathrm{dl}^{-1}$ ).

Table 1 Characteristics of investigated subjects

\begin{tabular}{|c|c|c|c|c|c|c|}
\hline & \multirow[b]{2}{*}{$n(\%)$} & \multirow{2}{*}{$\begin{array}{l}\text { Age (years)*, } \\
\text { median (IQR) }\end{array}$} & \multicolumn{2}{|c|}{ TSH $\left(\mu \cup \mathrm{ml}^{-1}\right)$, median (IQR) } & \multirow{2}{*}{$\begin{array}{c}\text { Thyroid volume }(\mathrm{ml}) \dagger \text {, } \\
\text { median (IQR) }\end{array}$} & \multirow{2}{*}{$\begin{array}{l}\text { Ioduria }\left(\mu \mathrm{g} \mathrm{dl}^{-1}\right) \dagger \\
\text { median }(\mathrm{IQR})\end{array}$} \\
\hline & & & $1989-1990$ & $1997-1999$ & & \\
\hline Females & $933(66 \%)$ & $37.8(21)$ & $1.34(0.85) \ddagger$ & $1.72(0.94)$ & $15.3(7.2)$ & $106.0(84)$ \\
\hline Males & $491(34 \%)$ & $39.2(21)$ & $1.19(0.84) \S$ & $1.27(0.78) \uparrow$ & $18.4(8.9) \|$ & 120.7 (93)\| \\
\hline Total & 1424 & $38(21)$ & $1.0(0.88) \ddagger$ & $1.19(0.89)$ & $16.3(8.6)$ & $111.6(89)$ \\
\hline
\end{tabular}

IQR - interquartile range; TSH - thyroid-stimulating hormone.

*Values from the study 1989-1990.

† Values from the study 1997-1999.

$\ddagger P<0.0001$ versus study $1997-1999$.

$\S P<0.001$ versus study $1997-1999$.

१ $P=0.03$ versus females.

$\| P<0.0001$ versus females. 
Iodine prophylaxis and hyperthyroidism

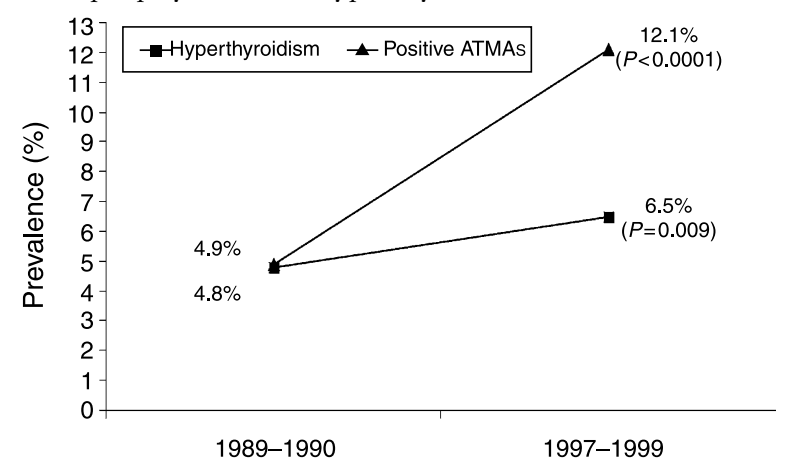

Fig. 1 Prevalence of hyperthyroidism (thyroid-stimulating hormone $<0.4 \mu \mathrm{U} \mathrm{ml}^{-1}$ ) and positive anti-thyroid microsomal antibodies (ATMAs) before (1989-1990) and just after (1997-1999) implementation of iodine prophylaxis

The median value of $\mathrm{FT}_{4}$ in 1997-1999 was $15.3 \mathrm{pmoll}^{-1}$ $\left(\mathrm{IQR}=3.1 ;\right.$ normal range $\left.=7.7-23.2 \mathrm{pmoll}^{-1}\right)$. The median age of subjects with hyperthyroidism was higher after implementation of iodine prophylaxis than prior to this action, 46.2 (IQR $=16.5)$ years versus 32.5 (IQR $=16.5)$ years. It is important to note that every subject from the studied population was $\sim 9$ years older during the research in the second phase of the survey (Table 2).

No significant correlation between the plasma TSH level and ioduria was found $(R=-0.06, P=0.08)$. Figure 2 shows the appropriate correlation graph. Typical intersex differences in thyroid volume were also significant in our study. Ioduria was significantly higher among males (medians 120.7 versus $106 \mu \mathrm{gl}^{-1}, P<0.0001$ )

\section{Discussion}

Iodine-induced hyperthyroidism may occur after a rapid increase of iodine supplementation in the condition of stable, chronic iodine deficiency. It is widely known that the benefits of the implementation of iodine prophylaxis strongly outweigh the risk of negative effects. In Poland, an evident decrease in the prevalence of goitre among schoolchildren was observed as a consequence of household salt iodisation ${ }^{6,7}$.

The median value of ioduria $\left(111.6 \mu \mathrm{gl}^{-1}\right)$ in 19971999 was evidently higher when compared with values found in the survey carried out in 1989-1990 (range 30-64 $\left.\mu \mathrm{gl}^{-1}\right)^{8}$.

The other well-evidenced consequences of that intervention are a drop in the plasma TSH concentration among neonates and diminished 24-hour thyroid radioiodine uptake in the population of Poland $d^{5,7,9,10}$.

In our study, performed early after the implementation of iodine prophylaxis, a significant rise in the prevalence of hyperthyroidism, mainly subclinical, and positive thyroid autoantibody were observed. At least in part, the increased autoimmunity could be related to thyroid function changes.

The plasma TSH level was not significantly correlated with ioduria. This indicates that a rapid increase in iodine intake rather than stable, adequate iodine intake is related to the temporary immunological and functional thyroidal disturbances in the population affected earlier by iodine deficiency.

A prospective trial in an iodine-deficient area of Morocco showed that rapid introduction of iodised salt did not provoke significant thyroid autoimmunity and hyperthyroidism ${ }^{11}$. A Polish survey conducted in the years 2000-2001, based on the regional hyperthyroidism registers, showed no serious excess iodine-induced hyperthyroidism $^{12}$. Only a transient increase in the prevalence of hyperthyroidism was observed after augmentation of the iodine content of table salt from 10 to $20 \mathrm{mg} \mathrm{KI} \mathrm{kg}^{-1}$ by the Austrian authorities in $1990^{13}$.

Szabolcs et al. presented a comparison of thyroid function in three groups of subjects over 60 years of age, living in areas with different levels of iodine - an iodinedeficient area in northern Hungary, a part of eastern Hungary with abundant iodine intake, and Slovakia, a country where obligatory iodinated salt prophylaxis has been in place since 1950. Hyperthyroidism was not distributed differently among these three groups ${ }^{14}$.

Table 2 Hyperthyroidism prevalence before and after implementation of iodine prophylaxis according to age and gender

\begin{tabular}{|c|c|c|c|c|c|c|}
\hline \multirow[b]{2}{*}{ Age groups (years) } & & \multirow[b]{2}{*}{$n$} & \multicolumn{2}{|c|}{$\begin{array}{c}\text { Before } \\
\text { supplementation }\end{array}$} & \multicolumn{2}{|c|}{$\begin{array}{c}\text { After } \\
\text { supplementation }\end{array}$} \\
\hline & & & $n$ & $\%$ & $n$ & $\%$ \\
\hline \multirow[t]{3}{*}{$16-30$} & Females & 298 & 21 & 7.0 & 22 & 7.4 \\
\hline & Males & 137 & 5 & 3.7 & 9 & 6.6 \\
\hline & Total & 435 & 26 & 6.0 & 31 & 7.1 \\
\hline \multirow[t]{3}{*}{$31-50$} & Females & 441 & 2 & 6.1 & 33 & 7.5 \\
\hline & Males & 233 & 10 & 4.3 & 11 & 4.7 \\
\hline & Total & 674 & 37 & 5.5 & 44 & 6.5 \\
\hline \multirow[t]{4}{*}{$>50$} & Females & 194 & 3 & 1.5 & 11 & 5.7 \\
\hline & Males & 121 & 2 & 1.7 & 6 & 5.0 \\
\hline & Total & 315 & 5 & 1.6 & 17 & 5.4 \\
\hline & & 1424 & 68 & 4.8 & 92 & 6.5 \\
\hline
\end{tabular}




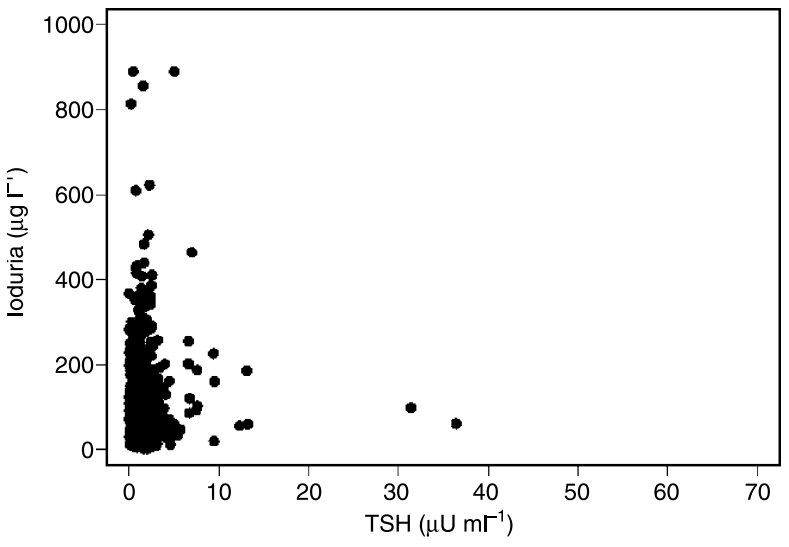

Fig. 2 Correlation between ioduria and thyroid-stimulating hormone (TSH) levels in the population of southern Poland just after implementation of iodine prophylaxis

We concluded that a sudden rise in iodine intake after implementation of iodine prophylaxis among adults from an area with iodine deficiency may lead to an increase in thyroid autoimmunity and prevalence of hyperthyroidism, possible early side-effects appearing to be only temporary and acceptable when compared with the evident benefits of adequate iodine intake.

\section{Acknowledgements}

Sources of funding: Our study was carried out within the nationwide MZ-XVII Research programme supported by the polish ministry of Health.

Conflict of interest declaration: No author had any conflict of interest.

Authorship responsibilities: F. G. designed and conducted the analysis and prepared the manuscript; M. B.-B. and M. T. collected the data and assisted with the current analyses; Z. S. contributed to study design, organisation and data assessment; A. B.-W. and B. H. made substantial contributions to the study analyses as well as to the writing of the paper.

\section{References}

1 Szybinski Z, Zarnecki A. Prevalence of goiter, iodine deficiency and iodine prophylaxis in Poland. Polish Journal of Endocrinology 1993; 44: 371-88.

2 Bar-Andziak E, Nauman J. Possible risk of iodine induced hyperthyroidism (IIH) as a consequence of obligatory iodine prophylaxis in Poland. Polish Journal of Endocrinology 1998; 49(Suppl. 1): 55-62.

3 Nauman J. The study on the effects of some prophylactic measures and radiological contamination in Poland after Czernobyl accident; introduction to the research programme MZ-XVII. Polish Journal of Endocrinology 1991; 42: 153-8.

4 Nauman J, Roszkowska H. Epidemiological foundation of population studies of MZ-XVII programme. Polish Journal of Endocrinology 1991; 42: 159-79.

5 Sandell EB, Kolthoff IM. Micro-determination of iodine by a catalytic method. Mikrochimica Acta 1937; 1: 9-25.

6 Szybinski Z. Results of the programmes on iodine deficiency in Poland and monitoring of mandatory model of iodine prophylaxis. Polish Journal of Endocrinology 1998; 49(Suppl. 1): 9-19.

7 Pniewska-Siark B, Bobeff I, Malagocka-Wojciechowska E, Ligocka E, Zarzycki B, Zarzycki J. Neonatal screening program for congenital hypothyroidism as a monitoring system of iodine deficiency in newborns and their mothers in the Lodz Macroregion. Polish Journal of Endocrinology 1998; 49(Suppl. 1): 77-83.

8 Dluzniewska K, Tylek D, Baranowska K, Drozdz R, Henning $\mathrm{J}$, Holynska B, et al. Evaluation of iodine levels in daily dietary intake and urine of persons participating in epidemiological studies in the Krakow macro-region after the disaster in Czernobyl and level of iodine in drinking water of that region. Polish Journal of Endocrinology 1991; 42: $241-51$

9 Golkowski F, Huszno B, Trofimiuk M, Sowinski J, Bandurska-Stankiewicz E, Dorant B, et al. Prevalence of goiter in schoolchildren - a study on the influence of adequate iodine prophylaxis in Poland. Journal of Endocrinological Investigation 2003; 26(Suppl. to No. 2): $11-15$.

10 Huszno B, Hubalewska-Hola A, Baldys-Waligorska A, SowaStaszczak A, Szybinski Z. The impact of iodine prophylaxis on thyroid 131-iodine uptake in the region of Krakow, Poland. Journal of Endocrinological Investigation 2003; 26(Suppl. to No. 2): 7-10.

11 Zimmermann MB, Moretti D, Chaouki N, Torresani $T$. Introduction of iodized salt to severly iodine-deficient children does not provoke thyroid autoimmunity: a one-year prospective trial in northern Morocco. Thyroid 2003; 13: 199-203.

12 Lewinski A, Szybinski Z, Bandurska-Stankiewicz M, Grzywa A, Karwowska A, Kinalska I, et al. Iodine-induced hyperthyroidism - an epidemiological survey several years after institution of iodine prophylaxis in Poland. Journal of Endocrinological Investigation 2003; 26(Suppl. to No.2): 57-63.

13 Weissel M. Legal augmentation of iodine content in table salt from 10 to $20 \mathrm{mg} \mathrm{KI} / \mathrm{kg}$ : documented effects a decade later. Experimental and Clinical Endocrinology and Diabetes 2003; 111: 187-90.

14 Szabolcs I, Podoba J, Feldkamp J, Dohan O, Farkas I, Sajgo $\mathrm{M}$, et al. Comparative screening for thyroid disorders in old age in areas with iodine deficiency, long-term iodine prophylaxis and abundant iodine intake. Clinical Endocrinology (Oxford) 1997; 47: 87-92. 